\title{
N uevos receptores nucleares heterodiméricos: reguladores metabólicos con impacto en fisiopatología y su proyección terapéutica en dislipidemias y diabetes mellitus
}

\author{
Víctor Cortés ${ }^{1}$, Nicolás Q uezadaa ${ }^{a}$ Attilio Rigotti ${ }^{1}$, \\ Alberto Maiz ${ }^{2}$. \\ New heterodimeric nuclear \\ receptors: key metabolic regulators \\ with relevance in the \\ pathophysiology and therapy of \\ dyslipidemias and diabetes mellitus
} and the homeostatic maintenance of body tissues. Thus, its malfunction may determine a variety of human disease conditions. A growing body of evidence has shown the overwhelming relevance of a new class of gene expression regulators: the heterodimeric nuclear receptors, a family of structurally related proteins involved in multiple biological functions. In response to activating ligands, these molecules bind to specific genomic regulatory regions where they can coordinately modify the transcriptional activity of several genes involved in the main metabolic pathways of lipids and carbohydrates in cells. These functional properties have stimulated the study of the relationships between heterodimeric nuclear receptors and various disease conditions, such as dyslipidemias and diabetes mellitus. Here we review the experimental, clinical and epidemiological evidences that support the relevance of these transcriptional regulators in the pathophysiology of the most prevalent and lethal diseases in Western countries. We also explore the potential therapeutic impact of new strategies based in the pharmacological modulation of the heterodimeric nuclear receptors. (Rev Méd Chile 2005; 133: 1483-92)

(Key Words: Diabetes mellitus; Hyperlipidemia; Receptors, cytoplasmic and nuclear)

\begin{abstract}
Recibido el 14 de julio, 2005. Aceptado el 20 de octubre, 2005.
Trabajo parcialmente financiado por el Proyecto Regular $\mathrm{N}^{\circ} 1030416$ del Fondo Nacional de Desarrollo Científico y Tecnológico de Chile (FONDECYT).

${ }^{1}$ Departamentos de Gastroenterología y ${ }^{2}$ Nutrición, Diabetes y Metabolismo, Facultad de Medicina, Pontificia Universidad Católica de Chile, Santiago, Chile.

aAlumno de Medicina, Pontificia Universidad Católica de Chile.
\end{abstract}

Correspondencia a: Dr. Alberto Maíz, Departamento de Nutrición, Diabetes y Metabolismo, Facultad de Medicina, Pontificia Universidad Católica de Chile, Marcoleta 367, Santiago, Chile. Fono: 56-2-3543862, Fax 56-2-6338298, Email: maiz@med.puc.cl 
L os receptores nucleares son factores transcrip_cionales que juegan un importante rol en la regulación de la expresión génica. Actualmente se conocen 50 proteínas pertenecientes a esta superfamilia»génica y entre ellas existe una notable similitud estructural (Figura 1). Después de interactuar con sus ligandos específicos, los receptores nucleares se unen a regiones específicas del genoma y modifican la transcripción de numerosos genes ${ }^{1}$. Históricamente, los receptores nucleares más estudiados han sido los de hormonas esteroidales (estrógenos, andrógenos, progesterona, glucocorticoides y mineralocorticoides). Estos receptores, característicamente unen con alta afinidad (Kd en el rango nanomolar) y especificidad a sus ligandos y forman homodímeros para interactuar con el $\mathrm{ADN}^{1,2}$.

Sin embargo, recientemente, la atención se ha volcado hacia otros receptores nucleares, para la mayoría de los cuales no existe claridad en cuanto a sus ligandos endógenos, genes blancos ni funciones fisiológicas. De ahí que, tradicionalmente, se les haya denominado receptores huérfanos»r2. En contraste con los receptores esteroidales clásicos, los receptores huérfanos unen sus ligandos con menor afinidad (Kd en el rango micromolar) y presentan un repertorio de ligandos más amplio ${ }^{3}$. Estos receptores funcionan predominantemente como heterodímeros del receptor retinoide X (RXR) (Figura 2), por lo que también se les conoce como receptores nucleares heterodiméricos»(RNH). Esta última característica es muy relevante para entender su funcionamiento $\mathrm{y}$ para plantear posibles estrategias terapéuticas basadas en su manipulación farmacológica.

La naturaleza de sus ligandos, junto con su capacidad para modificar la actividad transcripcional de múltiples genes relevantes en la homeostasis celular de lípidos, permiten plantear que los receptores nucleares heterodiméricos seńan reguladores fisiológicos del metabolismo lipídico ${ }^{2,3}$. En los últimos años, se han identificado y caracterizado molecularmente los receptores de ácidos grasos (PPARs, por peroxisome proliferators activated receptors), oxistero-

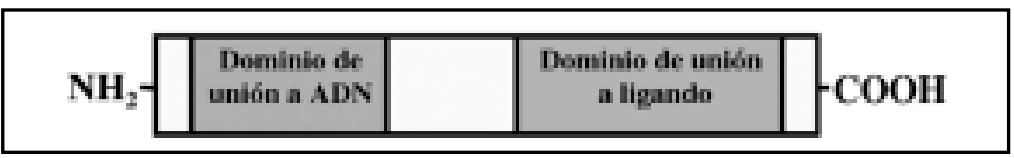

Figura 1. Estructura básica de la superfamilia de los receptores nucleares.

Aunque regulan una amplia diversidad de procesos fisiológicos, los receptores nucleares, poseen una estructura proteica muy conservada en la que destaca un dominio de unión a los ligandos respectivos, un dominio de unión al ADN y un dominio de homo/heterodimerización (no mostrado en la figura).

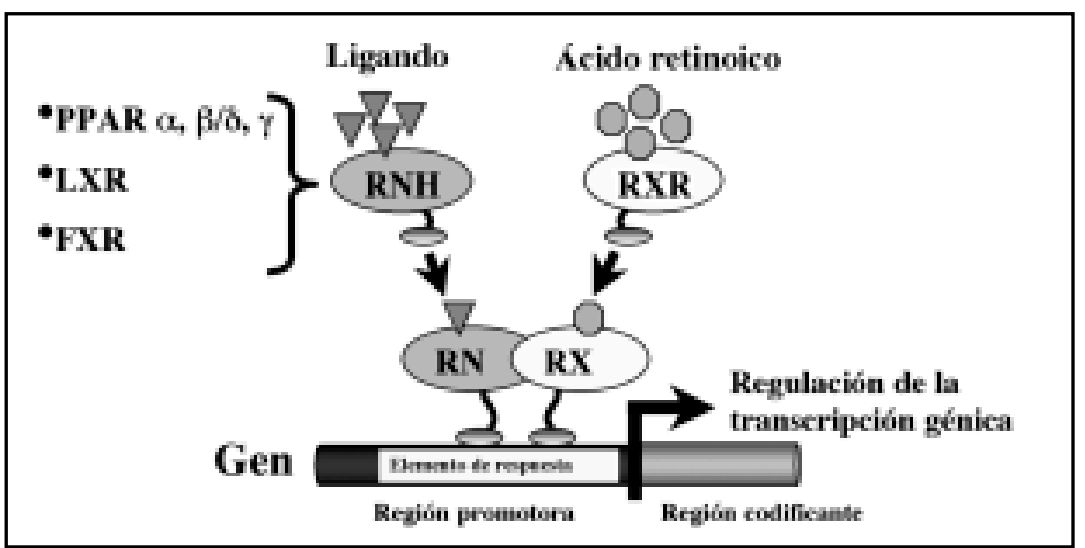

Figura 2. Mecanismo de acción de los receptores nucleares heterodiméricos.

Después de ser activados por sus ligandos específicos, este tipo de receptores nucleares forma heterodímeros con el receptor del ácido 9 cis-retinoico (Retinoid X Receptor, RXR). Este complejo se une a secuencias nucleotídicas específicas (elementos de respuesta) presentes en las regiones que controlan la expresión génica (promotores) de los genes blanco de los receptores nucleares, participando en el reclutamiento de otros factores proteicos (no mostrados en la figura) necesarios para la regulación de la actividad transcripcional de dichos genes. 
les (LXRs, por liver X receptors), ácidos biliares (FXRs, por farnesoid X receptors) y xenobióticos (SXR/PXR, por steroid xenobiotic receptor o su ortólogo murino, pregnane X receptor) (Tabla 1). Se ha reportado que algunos RNH tendrían, además, participación fisiológica en el metabolismo de los carbohidratos ${ }^{4,5}$, la respuesta inflamatoria local ${ }^{6-8}$, la regeneración tisu$\operatorname{lar}^{9}$, la diferenciación celular ${ }^{10}$, la apoptosis ${ }^{10}$ y el envejecimiento, ampliando su potencial impacto en la patogenia y el tratamiento de diversas enfermedades.

Los RNH más estudiados en su relación con la patología humana han sido los PPARs. Éstos constituyen una familia formada por tres isoformas: PPARa, PPARß/ס y PPAR ${ }^{11,12}$. El receptor PPAR $\alpha$ fue el primero en tener impacto en clínica, al descubrirse que los fibratos ejercían su efecto hipolipemiante a través de la unión y activación de este receptor ${ }^{13}$. Posteriormente, PPARy también adquirió un impacto terapéutico, porque las tiazolidinedionas son sus agonistas específicos ${ }^{14,15}$. La influencia de PPAR $\mathrm{y}$ PPARy en el metabolismo lipídico fue revisada recientemente por Uauy et al en esta revista ${ }^{16}$.

El presente artículo se centrará en los antecedentes más relevantes y recientes del rol de los nuevos $\mathrm{RNH}$ en el metabolismo de lípidos y carbohidratos y su relación con las dislipidemias, la diabetes mellitus y las complicaciones asociadas.

El receptor nuclear PPARß/ $\delta$. PPARß/ $\delta$ es el receptor menos caracterizado de su familia $y$, si bien sus ligandos endógenos se desconocen todavía, existen activadores farmacológicos que ya han sido probados en estudios en animales. Su alta expresión en hígado, intestino y macrófagos, ha hecho que se evalúe su importancia en el metabolismo lipídico ${ }^{11}$. Recientemente su expresión en el músculo esquelético ha sido implicada en la regulación de la sensibilidad insulínica ${ }^{17}$.

La participación de PPARß/ $\delta$ en el metabolismo lipídico queda de manifiesto con el estudio de ratones genéticamente manipulados en este receptor. Los animales deficientes en PPARß/ $\delta$ exhiben una reducción significativa en la masa de tejido adiposo pero, interesantemente, no desarrollan alteraciones relevantes en los lípidos plasmáticos ${ }^{18,19}$. Por otra parte, la sobreexpresión transgénica en adipocitos o músculo esquelético de una forma constitutivamente activa de $\mathrm{PPAR} / \delta$, protege a los ratones del desarmollo de obesidad, esteatosis hepática y dislipidemia y les confiere mayor sensibilidad insulínica cuando son expuestos a una sobrecarga dietética de grasa, posiblemente por activación de la oxidación de ácidos grasos y mayor termogénesis ${ }^{20}$. Adicionalmente, la sobreexpresión muscular de PPARß/ $\delta$ se asocia a un incremento en la capacidad para realizar ejercicio muscular prolongado ${ }^{17}$. Ratones alimentados con una dieta rica en grasa y tratados con agonistas farmacoló-

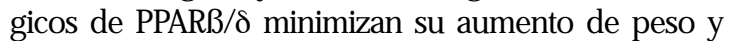
reducen su acumulación lipídica en músculo esquelético, hígado y tejido adiposo, presentando una menor resistencia insulínica ${ }^{21}$. Estos antecedentes nos ilustran una vez más la estrecha relación que existe entre el tejido adiposo y el músculo esquelético en la homeostasis de los lípidos y carbohidratos, y en la cual PPARß/ $\delta$ parece estar centralmente involucrado.

Además de influir directamente en la biología del tejido adiposo y en la sensibilidad insulínica, otros estudios indican que la activación de PPARß/ $\delta$ podńa favorecer, tanto el movimiento de colesterol desde los tejidos periféricos hacia el hígado (transporte reverso de colesterol), como la posterior eliminación de este lípido desde el organismo. Es así como el tratamiento de monos Rhesus obesos resistentes a la insulina con un activador farmacológico de PPARß/ $\delta$, logró simultáneamente aumentar el colesterol HDL ( 100\%), disminuir el colesterol LDL $(\sim 30 \%)$ y reducir los triglicénidos plasmáticos ( 56\%). Notablemente, estos animales también expenimentaron una disminución de $50 \%$ en su insulinemia, indicando un importante efecto insulino-sensibilizante de esta intervención ${ }^{22}$. Recientemente, se ha demostrado que la activación específica de PPARß/ $\delta$ en ratones, también incrementa la excreción fecal de esteroles neutros ( $80 \%$ de los cuales corresponden a colesterol), posiblemente por una menor absorción intestinal de colesterol secundania a una expresión intestinal reducida de NPC1L1, la proteína que controla la absorción intestinal de este lípido 23 .

Es posible que PPARß/ $\delta$ también influencie la respuesta vascular local a diversas noxas proaterogénicas. Se ha visto que la activación de PPARß/ $\delta$ ejerce un efecto antiinflamatorio local, con reducción de las moléculas de adhesión endoteliales, sustancias quimioatrayentes de macrófagos y enzimas pro-inflamatorias tales como COX-2 e iNOS ${ }^{7,8}$. Finalmente, se ha reportado que los agonistas de PPARß/ $\delta$ también podrían tener inesperadas propiedades anti-neoplásicas ${ }^{24,25}$.

En resumen, la activación de PPARß/ $\delta$ posiblemente sea beneficiosa, no sólo a través de la 


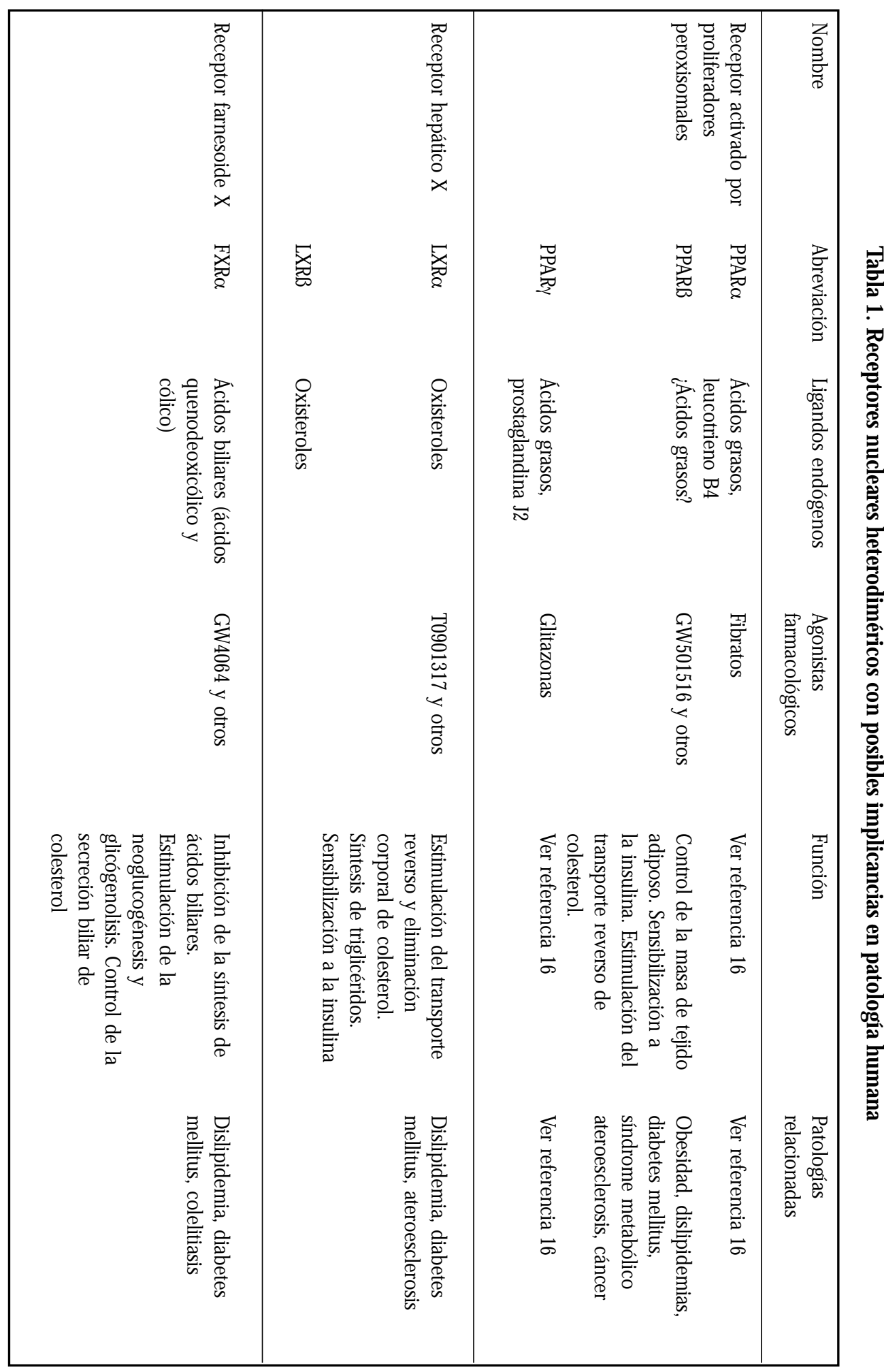


modificación favorable de factores de riesgo generales tales como dislipidemias, obesidad y resistencia insulínica, sino también por reducción de la inflamación vascular local. Esperamos estudios clínicos prospectivos que confirmen esta potencial influencia benéfica de la activación de PPARß/ $\delta$, la cual podría impactar favorablemente en una variedad de enfermedades, desde la obesidad, diabetes mellitus y aterosclerosis hasta el cáncer y enfermedades neuromusculares degenerativas.

Los receptores nucleares LXR y FXR. El descubrimiento de los ligandos endógenos de LXR y FXR ha establecido la importancia de estos receptores nucleares en el metabolismo hepático de coleste$\mathrm{rol}^{26-29}$. Sin embargo, y al igual que PPARß/ $\delta$, estos receptores nucleares también han sido implicados en la regulación de procesos tales como la inflamación, el metabolismo de los carbohidratos y la homeostasis energética ${ }^{5}$.
El hígado es el órgano central del metabolismo corporal del colesterol, no sólo por su alta actividad sintética, sino porque elimina reguladamente este lípido a través de la vía biliar, tanto como colesterol libre como transformado en ácidos biliares ${ }^{30}$. Durante la biosíntesis de ácidos biliares el colesterol es modificado oxidativamente hasta oxiesteroles. Estas moléculas activan potentemente $\operatorname{LXR}^{26,27}$ y estimulan la transcripción del gen que codifica la enzima colesterol-7 $\alpha$-hidroxilasa, aumentando la síntesis de ácidos biliares. Por su parte, los ácidos biliares neosintetizados en el hígado o captados desde la circulación, actúan como agonistas endógenos del receptor nuclear FXR ${ }^{28,29}$, el cual, a su vez, reprime la síntesis de ácidos biliares a través de la disminución de la transcripción del gen de la colesterol-7 $\alpha$ hidroxilasa. Así, estos dos receptores actúan como sensores y moduladores de un fino sistema de regulación recíproca, que mantiene la homeostasis del colesterol por medio de su conversión a ácidos biliares (Figura 3).

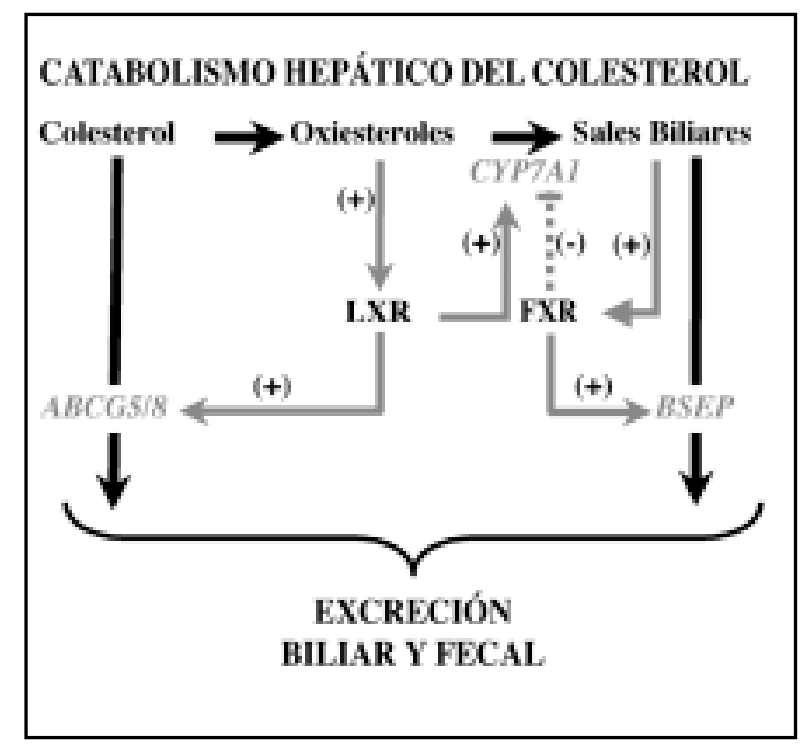

Figura 3. Relaciones funcionales entre los receptores nucleares LXRa y FXR en la regulación del metabolismo hepatocelular del colesterol.

La conversión del colesterol en sales biliares a nivel hepático constituye la principal vía de eliminación de colesterol del organismo y ocurre exclusivamente en los hepatocitos. Esta vía catabólica está finamente regulada por la acción coordinada de los receptores nucleares LXR y FXR. La activación de LXR $\alpha$ por oxiesteroles determina la regulación positiva de la transcripción del gen de la enzima colesterol $7 \alpha$ hidroxilasa (CYP7A1), la cual cataliza la etapa limitante en la síntesis de sales biliares. Por su parte, las sales biliares activan al receptor FXR, el cual, en forma opuesta a LXR $\alpha$, inhibe la expresión de CYP7A1. Adicionalmente, LXR y FXR aumentan el transporte de colesterol libre y sales biliares hacia la bilis aumentado la expresión de los genes ABCG5/8 y BSEP (por bile salt export pump), respectivamente, los cuales determinan la excreción de estos lípidos a través de la membrana canalicular hepatocitaria. 
El receptor LXR. El receptor LXR existe como dos isoformas funcionales: LXR $\alpha$ y LXRß. La primera es expresada mayoritariamente en el hígado y en menor medida en el intestino, tejido adiposo, riñón, bazo y macrófagos ${ }^{31}$. LXRß, en cambio, se expresa en casi todos los tejidos del organismo. Pese a su similitud, se piensa que ambas isoformas estarían involucradas en procesos biológicos distintos, aunque posiblemente relacionados. Aquí sólo se abordará LXRa, dado que hay muchos más antecedentes acerca del papel de esta isoforma en el metabolismo de lípidos y carbohidratos.

El fenotipo de los ratones transgénicos deficientes de LXR $\alpha$ señala la relevancia de este receptor en el metabolismo lipídico: presentan basalmente hipercolesterolemia y son incapaces de manejar sobrecargas dietéticas de colesterol, las que determinan mayor hipercolesterolemia y acumulación hepática masiva de este lípido ${ }^{32}$. Concordantemente, estos animales presentan un pool reducido de ácidos biliares y son resistentes a estímulos que normalmente incrementan su tamaño, indicando un defecto en el catabolismo terminal de colesterol a nivel hepático.

LXRa también regula la expresión de genes involucrados en el metabolismo de $\mathrm{HDL}^{33}$. Su activación resulta en mayor expresión de los genes ABCA1 y ABCG1/ABCG4 en macrófagos, facilitando la salida de colesterol hacia las partículas de $\mathrm{HDL}^{34,35}$. Además, LXRa aumenta la expresión de apolipoproteína $\mathrm{E}^{36}$, un importante componente de las HDL, que también facilita el eflujo de colesterol celular. Posiblemente como resultado de lo anterior, la activación farmacológica de LXR $\alpha$ aumenta significativamente los niveles de colesterol HDL en el ratón ${ }^{37}$. La estimulación de LXR $\alpha$ eleva los niveles plasmáticos de la enzima de transferencia de ésteres de colesterol (CETP) $)^{38}$, que cataliza el movimiento de colesterol desde las HDL hacia otras clases de lipoproteínas, promoviendo, en consecuencia, el transporte reverso de colesterol por una vía indirecta. En el hígado, además de estimular la síntesis de sales biliares ${ }^{32}$, LXRa incrementa la secreción biliar de colesterol propiamente tal, como resultado de una mayor expresión de los transportadores ABCG5 y ABCG8 en la membrana canalicular del hepatocito ${ }^{39}$. De manera coordinada, la activación de LXRa incrementa la expresión de los mismos transportadores en la superficie apical del enterocito ${ }^{39}$, con lo que disminuye la absorción intestinal de esteroles.
Estos dos efectos resultan, finalmente, en una mayor excreción de esteroles en las deposiciones y en un balance negativo de colesterol en el organismo (Figura 3). Los modelos experimentales citados permiten suponer que drogas capaces de activar LXR $\alpha$ deberían promover un perfil lipoproteico antiaterogénico, facilitando el movimiento de colesterol desde la periferia hacia el hígado y su eliminación por las heces.

Por otro lado, se ha reportado en modelos murinos de resistencia insulínica que agonistas sintéticos de LXR $\alpha$, incrementan significativamente la sensibilidad a esta hormona y reducen paralelamente la glicemia, tanto por reducción en la producción hepática de glucosa ${ }^{37,40}$ como por mayor captación tisular de glucosa dependiente de los transportadores GLUT1 y GLUT4 ${ }^{5}$.

Debe mencionarse que, no obstante los efectos beneficiosos comentados hasta aquí, el uso de activadores de LXR $\alpha$ induce hipertrigliceridemia en animales, aparentemente por una mayor lipogénesis hepática ${ }^{37,41,42}$. Por esta razón, se están desarrollando nuevos agonistas que mantengan los efectos beneficiosos sobre el transporte y absorción de colesterol sin afectar los niveles plasmáticos de triglicéridos. Estudios recientes han establecido que el empleo de agonistas de LXR $\alpha$ reduce significativamente el tamaño de las lesiones ateroescleróticas en modelos animales, no obstante la hipertrigliceridemia ${ }^{43}$. En conclusión, sólo estudios humanos de eficacia y seguridad permitirán establecer la eventual aplicación clínica de los activadores de LXR $\alpha$.

El receptor FXR. FXR es el receptor fisiológico de los ácidos biliares y su activación inhibe la transcripción de la enzima limitante en la biosíntesis de estos compuestos, la colesterol - $7 \alpha$-hidroxila$\mathrm{sa}^{28,29,33}$. Como otros receptores nucleares, la importancia de FXR en el metabolismo lipoproteico se estableció con el estudio de ratones deficientes en la expresión de este receptor. Éstos desarrollan un perfil lipídico caracterizado por hipercolesterolemia e hipertrigliceridemia, sugiriendo que FXR podría ser un factor relevante en el desarrollo y el manejo de las dislipidemias y la aterosclerosis ${ }^{44}$.

Dado su efecto represor sobre la síntesis de sales biliares ${ }^{28,29}$, el antagonismo farmacológico de FXR debería estimular la conversión de colesterol en sales biliares, aumentar su secreción hacia 
la bilis $\mathrm{y}$, en último término, su eliminación del organismo por vía fecal. Por lo tanto, el antagonismo farmacológico de FXR es, teóricamente, beneficioso en términos de generar un balance negativo de colesterol. En este sentido, se ha publicado recientemente que el esteroide vegetal gugulesterona es un antagonista del receptor FXR $\mathrm{y}$, concordantemente, su administración en ratones impide la acumulación hepática de colesterol en animales alimentados con un exceso de colesterol dietético ${ }^{45}$. Es interesante que el extracto natural de Commiphora mukul, que contiene gugulesterona, ha sido usado por largo tiempo en Asia para el tratamiento de dislipidemias y obesi$\operatorname{dad}^{46,47}$. Este extracto disminuye los niveles de colesterol LDL plasmático en humanos ${ }^{48}$ y está aprobado su uso como hipolipemiante en países orientales. No obstante lo anterior, en la literatura científica occidental existe sólo una publicación que evalúa el efecto metabólico en humanos de gugulípido, el compuesto natural que contiene gugulesterona. Inesperadamente, el tratamiento oral con este producto aumentó significativa, aunque muy discretamente, los niveles plasmáticos de colesterol LDL y disminuyó el colesterol HDL y los triglicéridos ${ }^{49}$. No obstante este aparente efecto negativo sobre los lípidos del plasma, este estudio no evaluó la eliminación fecal de sales biliares, la cual podría estar aumentada indicando un balance neto negativo del colesterol corporal. Por otro lado, se ha descrito que la gugulesterona es capaz de activar otros receptores nucleares, tales como el receptor de andrógenos, el receptor de glucocorticoides, el receptor de mineralocorticoides y el receptor de progesterona ${ }^{50}$, dificultando la interpretación de su efecto final en humanos. Por lo tanto, serán de gran interés los resultados que se obtengan con el uso de agonistas y antagonistas farmacológicos específicos para este receptor nuclear.

Se ha propuesto que FXR podría estar involucrado en el metabolismo de los carbohidratos y en el desarrollo de algunas manifestaciones metabólicas de la diabetes. Así, se ha observado que los niveles intracelulares de glucosa afectan la expresión hepatocelular de FXR, la cual está disminuida en los animales diabéticos ${ }^{51}$. Este mecanismo podría jugar un rol en el desarrollo de las dislipidemias mixtas observadas en la diabetes mellitus. Adicionalmente, la activación de FXR incrementa la expresión hepática de la enzima fosfoenolpiruvato carboxiquinasa, que cataliza la etapa limitante de la neoglucogénesis. Este resultado concuerda con una mayor secreción de glucosa en hepatocitos en cultivo tratados con agonistas naturales y sintéticos de FXR ${ }^{52}$, por lo que la activación de este receptor podría, hipotéticamente, conducir a un estado hiperglicémico. Más aún, la activación de FXR podría estimular la glicogenólisis y, por lo tanto, incrementar por esta otra vía la generación hepática de glucosa ${ }^{52}$. Concordante con estos antecedentes, el ratón deficiente de FXR exhibe una mayor tolerancia a la glucosa y una sensibilidad aumentada a la insulina ${ }^{52}$, lo cual reafirma que la inhibición terapéutica de FXR debiera ser beneficiosa para el metabolismo de los glúcidos en condiciones de resistencia insulínica.

Finalmente, existen estudios que indican que FXR podnía estar involucrado en la litiasis biliar. Análisis genéticos en cepas de ratones propensos a la colelitiasis han identificado a FXR como un gen asociado con el fenotipo litogénico ${ }^{53}$ y han demostrado un marcado aumento en la susceptibilidad a la colelitiasis observada en los ratones deficientes de FXR. Por el contrario, la activación de FXR reduce la saturación en colesterol de la bilis de ratones y protege contra el desarrollo de la enfermedad ${ }^{54}$. Por lo tanto, es posible que mutaciones o polimorfismos en el gen humano de FXR, que resulten en la pérdida total o parcial de la función de este receptor nuclear, expliquen una mayor susceptibilidad a esta enfermedad, y a la inversa, que la activación terapéutica de FXR mejore el perfil de lípidos biliares, reduciendo la litogenicidad de las personas de mayor riesgo para esta enfermedad.

El receptor RXR. Dado que los receptores nucleares revisados en este artículo heterodimerizan con RXR (Figura 2), la activación de este componente común podría tener un efecto múltiple e integral en las vías metabólicas reguladas por cada receptor particular ${ }^{55}$. De hecho, la activación de RXR con los agonistas farmacológicos conocidos como rexinoides, produce una disminución en los triglicéridos plasmáticos junto con un aumento en el colesterol HDL, sin modificar significativamente los niveles de colesterol LDL en modelos animales ${ }^{34}$. Por otro lado, los rexinoides estimulan la secreción biliar y, simultáneamente, disminuyen la absorción intesti- 
nal de colesterol como consecuencia de una inducción en la expresión de los transportadores ABCG5/ABCG8 en hígado e intestino ${ }^{39}$, generando una pérdida neta del colesterol corporal.

Los rexinoides también reducen la respuesta aterosclerótica en ratones, tanto aisladamente como en combinación con agonistas de PPAR $\alpha$, superando incluso la efectividad de agonistas de PPAR ${ }^{56}$. Por lo tanto, la utilización de estos fármacos en humanos podńa tener un efecto favorable tanto en el manejo de las dislipidemias como en la prevención y el tratamiento de la ateroesclerosis. Además, la activación farmacológica de RXR mejora significativamente el control glicémico en animales diabéticos ${ }^{57}$.

\section{COMENTARIO FINAL}

El estudio de los RNHs ha permitido profundizar el entendimiento de las bases moleculares de la regulación metabólica (Tabla 1), de modo que tenemos, como nunca antes, la posibilidad de intervenir racionalmente en el origen de las enfermedades más prevalentes y letales de hoy día. Como lo ilustran los datos comentados en este trabajo, es posible que en un futuro próximo se describan aplicaciones terapéuticas novedosas e inesperadas basadas en la modulación de éstos u otros receptores nucleares, de tal manera que el conocimiento de la biología básica de

\section{REFERENCIAS}

1. Francis GA, Fayard E, Picard F, AuwerX J. Nuclear receptors and the control of metabolism. Annu Rev Physiol 2003; 65: 261-311.

2. Chawla A, Repa JJ, Evans RM, Mangelsdorf DJ. Nuclear receptors and lipid physiology: opening the X-files. Science 2001; 294: 1866-70.

3. Gronemeyer H, Gustafsson JA, Laudet V. Principles for modulation of the nuclear receptor superfamily. Nat Rev Drug Discov 2004; 3: 950-64.

4. Rangwala SM, Lazar MA. Peroxisome proliferatoractivated receptor gamma in diabetes and metabolism. Trends Pharmacol Sci 2004; 25: 331-6.

5. Stefrensen KR, Gustafsson JA. Putative metabolic effects of the liver $\mathrm{X}$ receptor (LXR). Diabetes 2004; 53 Suppl 1: S36-42.

6. Joseph SB, CastriLo A, Laffitte BA, Mangelsdorf DJ, Tontonoz P. Reciprocal regulation of inflam- los RNHs casi con seguridad se traducirá en herramientas útiles para el tratamiento de nuestros pacientes.

\section{ABREVIATURAS}

ABC: ATP-binding cassette transporter (transportador con cassette de unión a ATP)

CETP: Cholesteryl ester transfer protein (proteína de transferencia de ésteres de colesterol)

COX2: Cyclooxygenase-2 (ciclooxigenasa-2)

GLUT: Glucose transporter (transportador de glucosa)

HDL: High density lipoprotein (lipoproteína de alta densidad)

iNOS: Inducible nitric oxide synthase (sintasa de óxido nítrico inducible)

LDL: Low density lipoprotein (lipoproteína de baja densidad)

FXRs: Farnesoid X receptors (receptores farnesoide $\mathrm{X}$ )

LXRs: Liver X receptors (receptores hepático X) NPC1L1: Niemann-Pick type C1-like 1 protein (proteína 1 similar a proteina de Niemann-Pick tipo C1)

PPARs: Peroxisome proliferator-activated receptors (receptores activados por proliferadores peroxisomales)

RNHs: Receptores nucleares heterodiméricos

RXR: Retinoid X receptor (receptor retinoide X)

mation and lipid metabolism by liver $\mathrm{X}$ receptors. Nat Med 2003; 9: 213-9.

7. Lee CH, Chawla A, Urbiztondo N, Luao D, Boisvert WA, Evans RM ET AL. Transcriptional repression of atherogenic inflammation: modulation by PPARdelta. Science 2003; 302: 453-7.

8. Tan NS, Michalk L, Di-Poi N, NG CY, Mermod N, RoBerTS AB ET AL. Essential role of Smad3 in the inhibition of inflammation-induced PPARbeta/ delta expression. Embo J 2004; 23: 4211-21.

9. Tan NS, Michalik L, Di-Poi N, Desvergne B, Wahli W. Critical roles of the nuclear receptor PPARbeta (peroxisome-proliferator-activated receptor beta) in skin wound healing. Biochem Soc Trans 2004; 32 (Pt 1): 97-102.

10. Rosen ED, Spiegelman BM. PPARgamma: a nuclear regulator of metabolism, differentiation, and cell growth. J Biol Chem 2001; 276: 37731-4.

11. Desvergne B, Wahli W. Peroxisome proliferator- 
activated receptors: nuclear control of metabolism. Endocr Rev 1999; 20: 649-88.

12. Torra IP, Chinetti G, Duval C, Fruchart JC, Staels B. Peroxisome proliferator-activated receptors: from transcriptional control to clinical practice. Curr Opin Lipidol 2001; 12: 245-54.

13. Gebel T, Arand M, Oesch F. Induction of the peroxisome proliferator activated receptor by fenofibrate in rat liver. FEBS Lett 1992; 309: 37-40.

14. Lehmann JM, Moore LB, SMith-Oliver TA, WiLison WO, WILSON TM, KuEWER SA. An antidiabetic thiazolidinedione is a high affinity ligand for peroxisome proliferator-activated receptor gamma (PPAR gamma). J Biol Chem 1995; 270: 12953-6.

15. Yki-JaRvinen H. Thiazolidinediones. N Engl J Med 2004; 351: 1106-18.

16. Uauy R, Martínez JI, Rojas CV. [Molecular nutrition, role of the PPAR system in lipidic metabolism and its importance in obesity and diabetes mellitus]. Rev Méd Chile 2000; 128: 437-46.

17. Wang YX, Zhang CL, Yu RT, Cho HK, Nelson MC, BaYUga-OCAMPO CR ET AL. Regulation of muscle fiber type and running endurance by PPARdelta. PLoS Biol 2004; 2: e294.

18. Peters JM, Lee SS, Li W, Ward JM, Gavrilova O, EVERETT C ET AL. Growth, adipose, brain, and skin alterations resulting from targeted disruption of the mouse peroxisome proliferator-activated receptor beta(delta). Mol Cell Biol 2000; 20: 5119-28.

19. Barak Y, Liao D, He W, Ong ES, Nelson MC, OLEFSKY JM ET AL. Effects of peroxisome proliferator-activated receptor delta on placentation, adiposity, and colorectal cancer. Proc Natl Acad Sci USA 2002; 99: 303-8.

20. Wang YX, Lee CH, Tiep S, Yu RT, Ham J, Kang H et AL. Peroxisome-proliferator-activated receptor delta activates fat metabolism to prevent obesity. Cell 2003; 113: 159-70.

21. Tanaka T, Yamamoto J, Imasaki S, Asaba H, Hamura $\mathrm{H}$, IKEDA Y ET AL. Activation of peroxisome proliferator-activated receptor delta induces fatty acid beta-oxidation in skeletal muscle and attenuates metabolic syndrome. Proc Natl Acad Sci USA 2003; 100: 15924-9.

22. Olvier WR Jr, Shenk JL, Snaith MR, Russell CS, Plunket KD, Bodkin NL et aL. A selective peroxisome proliferator-activated receptor delta agonist promotes reverse cholesterol transport. Proc Natl Acad Sci USA 2001; 98: 5306-11.
23. Van Der Veen JN, Kruit JK, Havinga R, Balier JF, Chimini G, Lestavel S et al. Reduced cholesterol absorption upon PPAR\{delta\} activation coincides with decreased intestinal expression of NPC1L1. J Lipid Res 2005; 46: 526-34.

24. Shureioi I, Jiang W, Zuo $X$, Wu Y, Stimmel JB, LEESNITZER LM ET AL. The 15-lipoxygenase-1 product 13-S-hydroxyoctadecadienoic acid downregulates PPAR-delta to induce apoptosis in colorectal cancer cells. Proc Natl Acad Sci USA 2003; 100: 9968-73.

25. Gupta RA, Wang D, Katkuri S, Wang H, Dey SK, DuBois RN. Activation of nuclear hormone receptor peroxisome proliferator-activated receptordelta accelerates intestinal adenoma growth. Nat Med 2004; 10: 245-7.

26. Janowski BA, Wily PJ, Devi TR, Falck JR, MangelsDORF DJ. An oxysterol signalling pathway mediated by the nuclear receptor LXR alpha. Nature 1996; 383: 728-31.

27. Lehmann JM, Kuewer SA, Moore LB, Smith-Oliver TA, Olvver BB, Su JL ET al. Activation of the nuclear receptor LXR by oxysterols defines a new hormone response pathway. J Biol Chem 1997; 272: 3137-40.

28. Makishima M, Okamoto AY, Repa JJ, Tu H, Learned RM, LUK A ET AL. Identification of a nuclear receptor for bile acids. Science 1999; 284: 1362-5.

29. Wang H, Chen J, HowSter K, SOWERs LC, Forman BM. Endogenous bile acids are ligands for the nuclear receptor FXR/BAR. Mol Cell 1999; 3: 543-53.

30. Dietschy JM, Turiey SD, Spady DK. Role of liver in the maintenance of cholesterol and low density lipoprotein homeostasis in different animal species, including humans. J Lipid Res 1993; 34: 1637-59.

31. REPA JJ, MANGeiSDORF DJ. The role of orphan nuclear receptors in the regulation of cholesterol homeostasis. Annu Rev Cell Dev Biol 2000; 16: 459-81.

32. PeEt DJ, Turiey SD, Ma W, Janowski BA, Lobaccaro JM, HAMMER RE ET AL. Cholesterol and bile acid metabolism are impaired in mice lacking the nuclear oxysterol receptor LXR alpha. Cell 1998; 93: 693-704.

33. Lu TT, REPA JJ, Mangelsdorf DJ. Orphan nuclear receptors as eLiXiRs and FiXeRs of sterol metabolism. J Biol Chem 2001; 276: 37735-8.

34. Repa JJ, Turiey SD, Lobaccaro JA, Medina J, Li L, Lustig $\mathrm{K}$ ET AL. Regulation of absorption and ABC1-mediated efflux of cholesterol by RXR heterodimers. Science 2000; 289: 1524-9. 
35. Wang N, Lan D, Chen W, Matsuura F, TaLl AR. ATPbinding cassette transporters G1 and G4 mediate cellular cholesterol efflux to high-density lipoproteins. Proc Natl Acad Sci USA 2004; 101: 9774-9.

36. Laffitte BA, Repa JJ, Joseph SB, Wilpitz DC, Kast HR, Mangelsdorf DJ et al. LXRs control lipidinducible expression of the apolipoprotein $\mathrm{E}$ gene in macrophages and adipocytes. Proc Natl Acad Sci USA 2001; 98: 507-12.

37. Schultz JR, Tu H, Luk A, Repa JJ, Medina JC, L L et AL. Role of LXRs in control of lipogenesis. Genes Dev 2000; 14: 2831-8.

38. LuO Y, TAL AR. Sterol upregulation of human CETP expression in vitro and in transgenic mice by an LXR element. J Clin Invest 2000; 105: 513-20.

39. Repa JJ, Berge KE, Pomajzl C, Richardson JA, Hobbs $\mathrm{H}$, Mangelsdorf DJ. Regulation of ATP-binding cassette sterol transporters ABCG5 and ABCG8 by the liver $\mathrm{X}$ receptors alpha and beta. J Biol Chem 2002; 277: 18793-800.

40. CaO G, LANg Y, Broderick CL, Oldham BA, Beyer TP, SCHMidT RJ ET AL. Antidiabetic action of a liver $\mathrm{x}$ receptor agonist mediated by inhibition of hepatic gluconeogenesis. J Biol Chem 2003; 278: 1131-6.

41. Horton JD, Shimomura I. Sterol regulatory element-binding proteins: activators of cholesterol and fatty acid biosynthesis. Curr Opin Lipidol 1999; 10: 143-50.

42. Repa JJ, Liang G, Ou J, Bashmakov Y, Lobaccaro JM, SHImOMURA I ET AL. Regulation of mouse sterol regulatory element-binding protein-1c gene (SREBP-1c) by oxysterol receptors, LXRalpha and LXRbeta. Genes Dev 2000; 14: 2819-30.

43. Joseph SB, McKimigin E, Pei L, Watson MA, Cowns AR, LAFFITte BA ET AL. Synthetic LXR ligand inhibits the development of atherosclerosis in mice. Proc Natl Acad Sci USA 2002; 99: 7604-9.

44. Sinal CJ, Tohkin M, Miyata M, Ward JM, Lambert G, GoNZALEZ FJ. Targeted disruption of the nuclear receptor FXR/BAR impairs bile acid and lipid homeostasis. Cell 2000; 102: 731-44.

45. Urizar NL, Liverman AB, Dodds DT, Silva FV, ORDENTLCH P, YAN Y ET AL. A natural product that lowers cholesterol as an antagonist ligand for FXR. Science 2002; 296: 1703-6.

46. Satyavati GV, Dwarakanath C, Tripathi SN. Experimental studies on the hypocholesterolemic effect of Commiphora mukul. Engl. (Guggul). Indian J Med Res 1969; 57: 1950-62.
47. Agarwal RC, Singh SP, Saran RK, Das SK, Sinha N, Asthana OP ET AL. Clinical trial of gugulipid-a new hypolipidemic agent of plant origin in primary hyperlipidemia. Indian J Med Res 1986; 84: 626-34.

48. Nityanand S, SRIvastava JS, Asthana OP. Clinical trials with gugulipid. A new hypolipidaemic agent. J Assoc Physicians India 1989; 37: 323-8.

49. Szapary PO, Wolfe ML, Bloedon LT, Cucchiara AJ, Dermarderosian AH, Ciriglano MD et al. Guggulipid for the treatment of hypercholesterolemia: a randomized controlled trial. JAMA 2003; 290: 76572.

50. Burris TP, Montrose C, Houck KA, Osborne HE, Bocchinfuso WP, Yaden BC ET AL. The hypolipidemic natural product guggulsterone is a promiscuous steroid receptor ligand. Mol Pharmacol 2005; 67: 948-54.

51. Duran-Sandoval D, Mautino G, Martin G, Percevault F, Barbier O, Fruchart JC et al. Glucose regulates the expression of the farnesoid $\mathrm{X}$ receptor in liver. Diabetes 2004; 53: 890-8.

52. Stayrook KR, Bramett KS, Savkur RS, Ficorim J, Cook T, CHRISTE ME et AL. Regulation of carbohydrate metabolism by the farnesoid $\mathrm{X}$ receptor. Endocrinology 2005; 146: 984-91.

53. Wittenburg H, Lyons MA, Li R, ChurchiL GA, Carey MC, Paigen B. FXR and ABCG5/ABCG8 as determinants of cholesterol gallstone formation from quantitative trait locus mapping in mice. Gastroenterology 2003; 125: 868-81.

54. Moschetta A, Bookout AL, Mangeisdorf DJ. Prevention of cholesterol gallstone disease by FXR agonists in a mouse model. Nat Med 2004; 10: 1352-8.

55. Szanto A, Narkar V, Shen Q, Uray IP, Davies PJ, NAGY L. Retinoid X receptors: X-ploring their (patho) physiological functions. Cell Death Differ 2004; 11 Suppl 2: S126-43.

56. Claudel T, Leibowitz MD, Fievet C et al. Reduction of atherosclerosis in apolipoprotein $\mathrm{E}$ knockout mice by activation of the retinoid $\mathrm{X}$ receptor. Proc Natl Acad Sci USA 2001; 98: 2610-5.

57. Shen Q, Cunne GW, Shulman GI, Leibowitz MD, DAVIES PJ. Effects of rexinoids on glucose transport and insulin-mediated signaling in skeletal muscles of diabetic $(\mathrm{db} / \mathrm{db})$ mice. J Biol Chem 2004; 279: 19721-31. 